
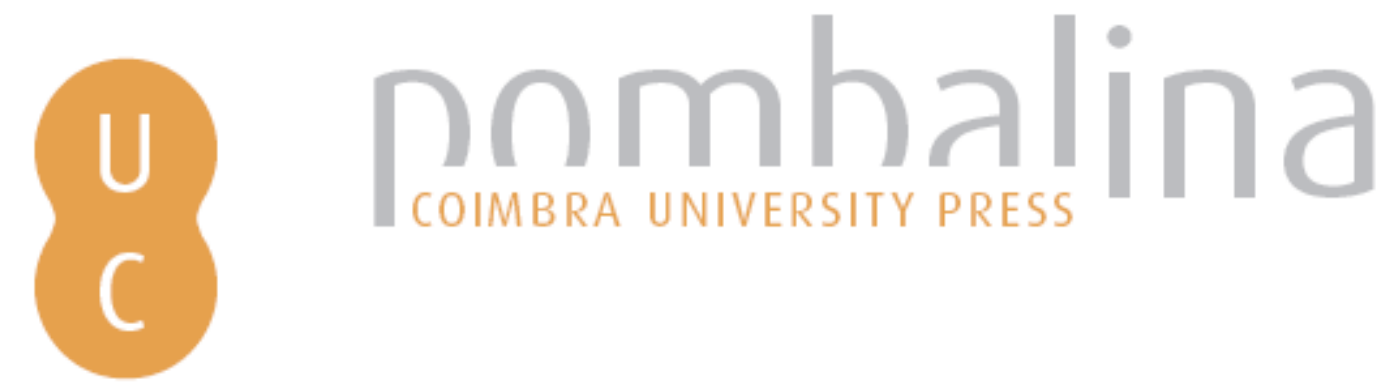

\title{
Sêneca, Epicteto, Medeia e a dissolução do trágico
}
Autor(es):
Dinucci, Aldo Lopes
Publicado por: Imprensa da Universidade de Coimbra; Annablume
URL
persistente:
URI:http://hdl.handle.net/10316.2/40903
DOI:
DOI:https://doi.org/10.14195/978-989-26-1278-2_22

Accessed : $\quad$ 26-Apr-2023 00:55:03

A navegação consulta e descarregamento dos títulos inseridos nas Bibliotecas Digitais UC Digitalis, UC Pombalina e UC Impactum, pressupõem a aceitação plena e sem reservas dos Termos e Condições de Uso destas Bibliotecas Digitais, disponíveis em https://digitalis.uc.pt/pt-pt/termos.

Conforme exposto nos referidos Termos e Condições de Uso, o descarregamento de títulos de acesso restrito requer uma licença válida de autorização devendo o utilizador aceder ao(s) documento(s) a partir de um endereço de IP da instituição detentora da supramencionada licença.

Ao utilizador é apenas permitido o descarregamento para uso pessoal, pelo que o emprego do(s) título(s) descarregado(s) para outro fim, designadamente comercial, carece de autorização do respetivo autor ou editor da obra.

Na medida em que todas as obras da UC Digitalis se encontram protegidas pelo Código do Direito de Autor e Direitos Conexos e demais legislação aplicável, toda a cópia, parcial ou total, deste documento, nos casos em que é legalmente admitida, deverá conter ou fazer-se acompanhar por este aviso.

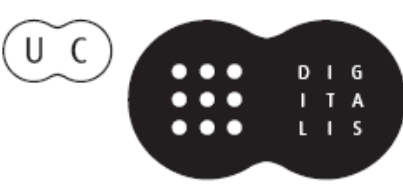




\section{O Livro do Tempo: Escritas e reescritas}

\section{Teatro Greco-Latino e sua recepção I}

Maria de Fátima Silva, Maria do Céu Fialho \& José Luís Brandão (coords.)

IMPRENSA DA UNIVERSIDADE DE COIMBRA

ANNABLUME 


\title{
Sêneca, Epicteto, Medeia e a dissolução do trágico (Seneca, Epictetus, Medea and the dissolution of the tragic)
}

\author{
Aldo Lopes Dinucci (aldodinucci@yahoo.com.br) \\ Pesquisador do CNPq, Brasil
}

\begin{abstract}
Resumo - Nesse artigo, partindo das reflexões de Epicteto sobre o trágico e da Medeia de Sêneca, veremos como as concepções estoicas desses filósofos diluem o trágico destruindo seus três princípios fundamentais: que as ações humanas sigam decretos divinos infalíveis, que a humanidade cumpra um papel especial no mundo, e que as ações humanas possam alterar o equilíbrio entre a ordem humana e a divina, provocando uma reação da justiça divina.

Palavras-chave: Tragédia, Estoicismo, Sêneca, Epicteto.
\end{abstract}

Aвstract - In this paper, we will see, from Epictetus' reflections about the tragic and from Seneca's Medea, how the stoic conceptions of these philosophers dilute the tragic destroying its three fundamental principles: that human actions follow divine decrees, that humanity plays a special role in the world, and that human actions can alter the balance between human and divine order, provoking a reaction from divine justice.

Keywords - Tragedy, Stoicism, Seneca, Epictetus.

São oito as tragédias atribuídas ao filósofo estoico, político e dramaturgo Lúcio Aneu Sêneca: Hércules Enlouquecido (Hercules Furens), As Troianas (Troades), Fedra (Phaedra), Agamenon (Agamemnon), Édipo (Oedipus), Tiestes (Thyestes), Hércules no Eta (Hercules Oetaeus) e Medeia (Medea). Há ainda As Fenícias (Phoenissae), obra que ou nos chegou mutilada ou não foi concluída. Além dessas, há também Otávia (Octavia), que, hoje se sabe, não foi realmente escrita por Sêneca, mas que, por tradição, é incluída entre as tragédias senequianas nas edições completas de seu teatro.

Essas tragédias senequianas exerceram profunda influência na Renascença Francesa, Italiana e Inglesa. Neste período, coube não aos poetas trágicos gregos, mas a Sêneca determinar o sentido do trágico. Shakespeare, diz-nos Arkin (1995: 1-8), teria lido apenas as tragédias de Sêneca, possivelmente no original em latim, e foi sem sombra de dúvida profundamente influenciado pelo romano, chegando a citá-lo nominalmente no Hamlet ${ }^{\text {. }}$.

Quanto à caracterização do trágico em Sêneca, cumpre notar em primeiro lugar que as suas tragédias são muito diferentes das gregas no que se refere à progressão da ação:

\footnotetext{
${ }^{1}$ Shakespeare 1860: 41.
} 
Enquanto essas são bastante movimentadas, as senequianas são estáticas. Há [...] falta de movimentação e de clímax. Parte-se de uma crise inicial, que se mantém até o fim sem maiores mudanças na ordem dos fatos. A catástrofe é prevista desde o início. Um patamar crítico substitui, por vezes, o ponto culminante ${ }^{2}$.

Assim, ler uma tragédia senequiana é uma experiência estranha para alguém acostumado com os trágicos gregos. Espera-se que algo ocorra, mas muito pouco acontece exteriormente. A ação trágica em Sêneca é interior: desvenda-se a cadeia de pensamentos do personagem, descortinam-se suas dúvidas, suas paixões, seus temores, seus furores, enquanto o personagem busca tomar uma decisão e agir. Há uma atmosfera de tensão, essa tensão que antecede as grandes decisões, e uma angústia talvez comparável ao ato de acompanhar pessoalmente as últimas horas de um paciente em estado terminal cuja morte não causa qualquer surpresa, mas tão somente confirma dolorosamente o que já se anunciava como certo.

Além disso, as tragédias senequianas, ao contrário das gregas, não são escritas tendo em vista a encenação teatral. Embora venham sendo encenadas no Ocidente desde a Renascença, elas foram concebidas para serem lidas nos círculos intelectuais da Roma Imperial. Enquanto as tragédias gregas eram compostas para serem encenadas durante as Dionisíacas, as festividades religiosas em honra ao deus Dioniso, as de Sêneca, feitas para leituras privadas, têm um sentido filosófico, que podemos qualificar de anti-trágico: os destinos dos personagens trágicos de Sêneca não são ditados pelos deuses, como nas tragédias gregas, mas são os próprios personagens que os fazem, tomando decisões em meio a uma grande tensão.

Assim, enquanto é objeto de amplo debate resgatar o sentido original das tragédias gregas, as tragédias de Sêneca têm um sentido evidentemente filosófico. As tragédias gregas apontam para a incomensurabilidade entre o humano e o divino, ao mesmo tempo em que fazem aquele absolutamente dependente deste, pois o divino, no sentido trágico, embora humanamente incompreensível e inabordável, determina pelos fados a sorte dos homens. Assim, pode-se dizer que o trágico grego é o modo que os gregos encontraram para atualizar e revigorar os mitos que se viam enfraquecidos naqueles tempos em que a noção de virtude fundada na estirpe e no sangue se esvanecia diante da democracia e da tirania. Em Sêneca, nada temos do gênero. A tragédia senequiana não se propõe de modo algum a revigorar os mitos, mas a superá-los totalmente: Sêneca considera os mitos inúteis para a compreensão do real, vendo a compreensão popular dos mitos apenas como uma forma de atirar os homens nas trevas da ignorância e de

\footnotetext{
${ }^{2}$ Cardoso 1997: 15 .
} 
crivá-los de medos tolos e inconsistentes, como, por exemplo, o medo da morte. Quanto a isso, ele próprio nos diz:

Mesmo quando tu tiveres te persuadido serem essas coisas fábulas e nada restar para que os mortos temam, outro medo se insinua. Igualmente os homens temem, então, tanto que não estejam nos infernos quanto que não estejam em parte alguma ${ }^{3}$.

Afora o logos estoico identificado com Zeus, logos que é uma retomada da noção heraclítica homônima, Sêneca simplesmente não leva a sério os mitos, chegando a deixar em seu testamento uma recomendação para que seu corpo fosse cremado sem qualquer cerimônia religiosa, recomendação que foi rigorosamente cumprida. Se os demais deuses aparecem em seus escritos, nada são senão personagens com potencial dramático. Por exemplo, na célebre obra Apokoloquintosis, em que Sêneca ridiculariza a divinização do falecido imperador Cláudio, a assembleia dos deuses olímpicos, afora os nomes divinos, em nada difere, em razão da balbúrdia e dos apartes, de uma assembleia de homens exaltados ${ }^{4}$.

Para Sêneca, portanto, os mitos não têm qualquer importância no que se refere ao sentido das ações humanas, pois, como observamos acima, enquanto para o trágico grego os deuses determinam o curso dos acontecimentos humanos, para Sêneca são os homens que fazem seu próprio destino através de suas tomadas de decisão. Investiguemos a razão de tal coisa começando por citar o que Zélia de Almeida nos fala quanto a isso:

Um dos traços marcantes a caracterizar as figuras de Sêneca é a luta que enfrentam em seu íntimo e que se trava entre as paixões e a razão. As personagens são dotadas de livre-arbítrio e têm consciência de que, se não são totalmente donas de seu destino, têm possibilidade de fazer o bem e evitar o mal. O fatalismo, presente na maioria das tragédias gregas, é substituído, nas de Sêneca, pelo drama psicológico (Cardoso 1997: 16).

Infelizmente nenhuma reflexão filosófica sobre o trágico do punho do próprio Sêneca chegou até nós para nos possibilitar um desenvolvimento dessa questão e explicar precisamente a razão pela qual ocorre, nas tragédias senequianas, essa inversão que, ao tirar dos deuses a responsabilidade pelos atos humanos, faz do homem o senhor de seu próprio destino. Porém, afortunadamente nos chegaram a esse respeito as reflexões de Epicteto exatamente sobre a crítica estoica ao trágico tal como era compreendida pelos gregos:

\footnotetext{
${ }^{3}$ Sen. Ep. 82.16.

${ }^{4}$ Sen. Apocol.
} 
Qual é a razão de se dar assentimento a algo? Parecer que é <o caso>. Com efeito, não é possível dar assentimento ao que parece que não é o caso. [...] Porque esta é a própria natureza do pensamento: inclinar-se para as coisas verdadeiras, estar descontente com as coisas falsas, suspender o juízo em relação às coisas incertas. [...] Quando, portanto, alguém dá assentimento ao que é falso, sabe tu que ele não desejou assentir [...] E então, o que temos tal como o verdadeiro e o falso em relação às ações? O que convém e o que não convém, o que é útil e o que é inútil, o que está de acordo comigo e o que não está, e as quantas coisas semelhantes a essas.5.

O texto de Epicteto parte da noção estoica de assentimento (synkatathesis). O assentimento é o ato que a alma humana realiza ao admitir como verdadeira uma determinada representação (phantasia). Por exemplo, alguém vestido de gorila assusta um menino que passa pela rua. Se esse menino achar que é realmente um gorila e, consequentemente, tomar por verdadeira a aparência ou representação que tem diante de si, se assustará e fugirá. E fará isso por considerar que essa é a linha de ação a se tomar quando se tem diante de si um animal feroz. Porém, se o menino compreender que se trata de um homem com uma fantasia de gorila, não se assustará, mas rirá. Assim, a atitude do menino será determinada por sua opinião em relação àquilo que percebe diante de si e não o contrário. Dessa forma, ninguém errará ou agirá equivocadamente por querer, mas por considerar equivocadamente ser tal curso de ação o melhor. $\mathrm{O}$ estoicismo aqui é absolutamente socrático, pois, para Sócrates, de acordo com sua tese da impossibilidade da akrasia, todos os homens buscam a felicidade e, portanto, quando erram e se afastam dela, o fazem involuntariamente. Esse texto de Epicteto nos é mais precioso ainda porque a seguir ele toca justamente no caso de Medeia citando a tragédia de Eurípedes:

Como aquela que diz: "Agora entendo que estou a ponto de executar tais atos criminosos. É a cólera o que há de mais forte entre meus desejos?”. Por isso mesmo ela pensa que agradar à cólera e punir o homem é mais vantajoso que conservar os filhos sãos e salvos. "Sim, mas ela enganou-se por completo". Mostra a ela, de modo claro, que se enganou por completo e ela não realizará o ato; <porém>, na medida em que não o demonstres, pelo que ela deixar-se-á conduzir senão pela aparência ${ }^{7}$ ? (9) [...] Por que, portanto, és hostil com ela? Porque a infeliz se enganou a respeito das melhores coisas e tornou-se de ser humano em víbora?

\footnotetext{
${ }^{5}$ Epict. Diss. 1. 28. 1.

${ }^{6}$ Fala de Medéia na Medéia de Eurípedes (E. Med. 1078-1079).

${ }^{7}$ Isto é: senão pelo que lhe parece ser a verdade.

${ }^{8}$ Epict. Diss. 1. 28. 7-9.
} 
Assim, Epicteto aplica a teoria estoica ao caso da personagem Medeia: seguindo os conceitos da Filosofia do Pórtico, Medeia teria agido em nome da paixão: ela assassinara os próprios filhos por considerar que vingar-se do marido que a abandonara era a melhor coisa a ser feita. Epicteto, também através dessa mesma reflexão, conclui que não se deve odiá-la nem hostilizá-la em razão de seu ato: sua atitude não revela maldade, mas tão somente ignorância. $\mathrm{O}$ erro humano tem como explicação um falso juízo e, no caso particular de Medeia, esse erro foi levar a sério a representação da ira e deixar-se conduzir por ela. Epicteto, a seguir, estende essa reflexão a todas as ações humanas:

De modo que também o princípio das grandes e terríveis ações é assim como esse? Este sim e não outro. A Ilíada nada é senão uma representação e o uso das representações. Pareceu bom para Alexandre levar a mulher de Menelau, pareceu bom para Helena deixar-se conduzir por Alexandre. Se, com efeito, parecesse a Menelau um ganho ser privado daquela mulher, o que aconteceria? Perder-se-ia não somente a Ilíada, mas também a Odisséia9 .

Desse modo, Epicteto se coloca contra o fatalismo trágico. As "tragédias" humanas não ocorrem devido a decretos implacáveis promulgados por deuses voluntariosos e irracionais, mas são causadas por escolhas humanas equivocadas e movidas pela paixão. O centro da reflexão sobre as ações humanas se desloca, portanto, para a própria escolha dos homens, os quais são agora vistos como os verdadeiros responsáveis pelos seus erros. Na sequência do texto, Epicteto desliga mais uma das chaves do maquinário teatral trágico grego. Outra nota desse gênero de tragédia é o seu caráter profundamente antropocêntrico: embora os homens não determinem seu próprio destino, ainda assim eles estão no centro da cena, pois, afinal de contas, os deuses se dedicam a decretar seus destinos. O enredo trágico grego põe em destaque o sofrimento e a impotência dos homens diante do destino, e a sua dramatização objetiva provoca a empatia do espectador em relação aos heróis trágicos. O ponto de vista estoico, porém, é naturalista: as calamidades humanas são postas em pé de igualdade com os demais acontecimentos desastrosos do mundo. Epicteto deixa isso bem claro em sua reflexão sobre o trágico:

E ainda dizes serem estas as mais importantes? As guerras, as disputas políticas, a perda de muitos homens e o aniquilamento de cidades? E o que há de grande nisso? - É algo grande matar muitos bois e muitos carneiros e incendiar e destruir muitos ninhos de andorinhas ou de cegonhas? Estas coisas são, portanto, semelhantes àquelas? - Muito semelhantes. São destruídos os corpos dos homens, assim como os dos bois e dos carneiros.

\footnotetext{
${ }^{9}$ Epict. Diss. 1. 28. 11-13.
} 
São incendiadas as pequenas casas dos homens, assim como os ninhos das cegonhas $^{10}$.

Portanto, numa perspectiva estoica, eventos como, por exemplo, a morte de uma andorinha e a morte dos filhos de Medeia se equivalem. O que realmente diferencia uma coisa da outra é que as calamidades humanas têm sua origem na ignorância dos homens e nas subsequentes escolhas equivocadas. No mais, tudo é equiparável e absolutamente natural. Epicteto resume suas reflexões sobre o trágico com as seguintes palavras:

Jamais nenhum entre nós fará nada ao acaso. Mas, quando a primeira e única razão é agir corretamente ou errar, ser feliz ou infeliz, ser não-afortunado ou afortunado, unicamente aqui somos irrefletidos e impetuosos. De modo algum $<$ utilizo> algo semelhante [...] a uma régua, mas algo aparece e imediatamente sigo o que aparece. Sou, pois, melhor, que Agamenon e Aquiles porque esses, em razão de seguirem as aparências, façam e sofram tais males? Não ajo também tão somente sob o influxo da aparência? E qual tragédia possui outro princípio? [...] Como são chamados todos os que seguem a aparência? Loucos - Com efeito, agimos de modo diferente? ${ }^{11}$

Isto é: cada qual fará inexoravelmente o que lhe parecer ser o melhor. A questão é que isso que parece o melhor muitas vezes não o é realmente. Assim, o único modo de o homem não cometer tantos erros "trágicos" é refletir antes de agir e não ceder a impulsos passionais. $O$ primeiro passo para combater a loucura que é considerar verdadeira uma falsa representação é a confissão da própria ignorância. Essa confissão tem caráter terapêutico, pois possibilita que o homem crie para si mesmo a oportunidade de começar a se questionar e refletir, o que não faria considerando-se sábio.

Agora, tendo em vista essas reflexões filosóficas do Estoicismo quanto ao trágico, voltemos nosso olhar sobre a Medeia de Sêneca. Essa obra inspira-se na homônima de Eurípedes, embora, como nos diz Agustín Blanquez ${ }^{12}$, provavelmente tenha sido influenciada por outra tragédia homônima perdida de Ovídio. O argumento é o seguinte: Medeia, uma grande feiticeira, refugia-se em Corinto com Jasão e os dois filhos do casal. Jasão, porém, desposa Creusa, filha do rei de Corinto, Creonte. Tendo sido decretada a sua expulsão de Corinto, Medeia decide vingar-se de Jasão. Solicita um adiamento de um dia para a expulsão sob o pretexto de despedir-se dos filhos. Entrementes, envia um manto enfeitiçado a Creusa que, ao vesti-lo, morre envolta em chamas

\footnotetext{
${ }^{10}$ Epict. Diss. 1. 28. 14-16.

${ }^{11}$ Epict. Diss. 1. 28. 29-33.

12 Blanquez 1958: 15.
} 
juntamente com seu pai. Depois disso, Medeia degola seus próprios filhos, um dos quais diante de Jasão e do povo de Corinto, o que evidencia ainda mais o caráter vingativo da ação de Medeia, que transforma sua vendetta numa espetacular demonstração de poder, escapando em seguida numa carruagem puxada por duas serpentes.

Interpretaremos então, à luz do que até aqui vimos, o trecho da Medeia senequiana onde a personagem Medeia toma a decisão de assassinar os filhos, observando atentamente o modo como o dramaturgo e filósofo romano descreve o processo de tomada de decisão da personagem que acaba por levá-la a assassinar a própria prole.

No prólogo da tragédia, Medeia encontra-se num transe de ira e ressentimento, invocando os deuses para que matem a família de Creonte: "Matai a nova esposa, matai o sogro e toda a família real. $\mathrm{E}$ a mim, dai outro mal, mais terrível que a morte, para que eu possa oferecê-lo ao meu esposo"13. Medeia já está decidida a vingar-se e ciente do curso de ação que irá empreender. Porém, em seu âmago entra em cena um conflito entre o amor que ela acalenta pelos filhos e o desejo de vingar-se: "Quando eu dava à luz os meus filhos, dava à luz a minha vingança" ${ }^{14}$, diz Medeia que, juntando forças, tenta calar seu amor maternal evocando imagens de crimes e violência e dizendo a si mesma:

Deixa de lado o medo feminino e reveste teu espírito com todas as crueldades do Cáucaso [...] feridas, mortes, membros esparsos e sem exéquias [...] Tudo isso eu fiz, quando virgem; é preciso que minha dor se levante ainda mais terrível: agora que sou mãe, meus crimes devem ser maiores. Arma-te de cólera, prepara-te para aniquilar com um furor que vai até o paroxismo ${ }^{15}$.

Medeia, ao ouvir o canto nupcial da cerimônia que unirá trágica e brevemente Jasão e Creusa, enche-se ainda mais de ódio: recorda-se então dos crimes que ela mesma cometera para proteger Jasão, como o assassinato de seu próprio irmão, cujo corpo esquartejara e lançara pedaço por pedaço ao mar, para que seu pai Eetes parasse para recolher os restos mortais do filho e ela pudesse escapar com Jasão ${ }^{16}$.

Entretanto, para exercer com mais eficácia a sua vingança, Medeia diz a Jasão que pretende se retirar para sempre ${ }^{17}$, e prepara o manto enfeitiçado que será entregue por seus filhos a Creusa. Esta morre, e o palácio de Creonte arde em chamas. Medeia prepara-se então para o ato final da vingança concebida

\footnotetext{
${ }^{13}$ Sen. Med. $17-19$.

${ }^{14}$ Sen. Med. 23-26.

${ }^{15}$ Sen. Med. 43 sqq.

${ }_{16}$ Sen. Med. 116-149.

${ }^{17}$ Sen. Med. 285-290.
} 
para infringir o maior sofrimento possível a Jasão. Aí se evidencia de maneira plena e vigorosa o conflito entre o desejo de se vingar e o amor maternal:

Para que hesitar, ó minha alma? Estou seguindo teu infeliz ímpeto [...] Não há mais nada de sagrado para ti, manda embora o pudor: pequena é a vingança que deixa puras as mãos. Inflama novamente teus furores, excita tua indolência que se está afrouxando, faze brotar do fundo do coração os teus antigos ímpetos ${ }^{18}$.

Diante da realização do ato final de sua vingança, Medeia hesita. Porém sua ira vai encontrar apoio na satisfação por antigos crimes, como o assassinato do próprio irmão que ela celebra a seguir de forma macabra:

Agora é que sou Medeia: meu talento tornou-me grande no mal. Sou feliz, sim, sou feliz por ter cortado a cabeça de meu irmão; feliz por ter esquartejado seu corpo [...] Ó meu ódio, tu não deves senão procurar um objeto: seja qual for o crime, tua mão não será inexperiente ${ }^{19}$.

A luta entre as paixões segue seu curso diante da ação iminente. $\mathrm{O}$ amor maternal, então, apresenta seus argumentos diante da alma de Medeia tomada pela ira e, por um momento, Medeia, tocada pelo amor pelos filhos, parece que vai recuar e poupá-los: "Meu ódio abandonou-me e o amor materno reaparece inteiro em mim, afastando os sentimentos da mulher. Eu, eu vou derramar o sangue dos meus próprios filhos, de minha própria prole? Inspira-te melhor, ó minha demente cólera!" ${ }^{20}$. Médeia é tomada pela indecisão: "Ó minha alma, tu vacilas. Por quê? Por que as lágrimas banham o meu rosto, porque sou arrastada por impulsos contraditórios, entre o ódio e o amor?”21. Ela chega a chamar os filhos para junto de si para abraçá-los, quando a ira novamente se impõe com um pretexto: a morte dos filhos vingará seu pai e seu irmão que foram sacrificados em nome de Jasão. O pensamento é evidentemente torto, mas, é claro, Medeia está tomada pela paixão da ira e, neste estado passional e patético, a razão não pode mais operar, já foi tragada pelo fluxo da ira que consegue, por fim, persuadir a alma ferida de Medeia a tomar a decisão fatal e matar seus próprios filhos. Então, como que para evidenciar o estado de loucura de Medeia quando ela dá assentimento à paixão da ira, o espectro do irmão se manifesta a ela, e Medeia se oferece para sacrificar o filho de modo a apaziguar os manes do irmão que ela mesma matara:

\footnotetext{
${ }^{18}$ Sen. Med. 893 sqq.

${ }^{19}$ Sen. Med. 910 sqq.

${ }^{20}$ Sen. Med. 930 sqq.

${ }^{21}$ Sen. Med. 937.
} 
De quem é a sombra hesitante que avança arrastando seus membros esquartejados? É meu irmão: pede vingança. Ele será vingado [...] Deixa-me a mim mesma e serve-te, ó meu irmão, de minha mão, que sabe segurar a espada - Eis a vítima com a qual vou aplacar teus manes (ela mata um de seus filhos) ${ }^{22}$.

Com um conflito menos intenso, Medeia, diante de Jasão, matará também seu outro filho. E fugirá, incólume, aos céus, num carro puxado por duas serpentes. A fala final da tragédia é de Jasão: "Sim, vai pelos infinitos espaços do céu: para provar que não há deuses lá onde tu te elevas”23. Os deuses não mais explicam os atos humanos: tendo o homem atingido, por assim dizer, a Idade da Razão, torna-se também responsável por seus atos, senhor de si mesmo. Também não há no trágico senequiano uma Nêmesis universal operando, como na tragédia grega, para restaurar o equilíbrio que a ação criminosa e ensandecida de Medeia teria rompido. Esse é o último elemento antropomórfico que Sêneca retira da tragédia: nem os deuses determinam as ações humanas nem as ações humanas podem abalar o equilíbrio entre a ordem humana e a divina. Após realizar seus crimes, Medeia escapa incólume exteriormente e não haverá deus algum que a detenha e exerça sobre ela a justiça. A única marca que levará é interior: "Ó minha dor, não tenho mais nada para te sacrificar" ${ }^{24}$. O mundo seguirá seu curso indiferente e silencioso: o logos universal nada tem a fazer sobre o caso de Medeia e seus filhos: a morte deles, em termos cósmicos, é equivalente à destruição de um ninho de cegonhas ou à morte de uma andorinha.

\footnotetext{
${ }^{22}$ Sen. Med. 963 sqq.

${ }^{23}$ Sen. Med. 1026-1027.

${ }^{24}$ Sen. Med. 1019-1020.
} 


\section{Bibliografia}

Arkin, B. (1995), "Heavy Seneca, his influence on Shakespeare's Tragedies", Classics Ireland 2. 2: 1-16.

Blanquez, A. (1958), Aneu Sêneca, Teatro Completo. Barcelona: Iberia.

Cardoso, Z. A. (1997), As Troianas. São Paulo: Ucitec.

Epicteto (2000), The Discourses as reported by Arrian. Harvard: Loeb.

Sêneca (2001), Epistles 66-92. Trad. Gummere, R. M. Harvard: Loeb.

Sêneca (1973), Consolação à minha mãe Hélvia, Da Tranquilidade da Alma, Medeia, Apocoloquintose do Divino Cláudio. Trad. Agostinho da Silva. São Paulo: Abril Cultural.

Sêneca (1917), Tragedies. Trad. Miller, F. J. Harvard: Loeb.

Shakespeare (1860), Hamlet. Londres: Torrey.

Tácito (2000), Anais. Trad. Pereira, L. São Paulo: Tecnoprint. 